\title{
Comparative Assessment of the Fatty Acid Profiles of Crude Oils Extracted from Seeds of Selected Tea (Camellia sinensis L.) Cultivars
}

\author{
Kelvin Omondi George ${ }^{1,2}$, John K. Wanyoko33, Thomas Kinyanjui' ${ }^{2}$, Kelvin O. Moseti ${ }^{3 *}$, \\ Francis N. Wachira4 \\ ${ }^{1}$ Nairobi Bottlers Limited, Nairobi, Kenya \\ ${ }^{2}$ Department of Chemistry, Egerton University, Njoro, Kenya \\ ${ }^{3}$ Kenya Agricultural and Livestock Research Organization, Tea Research Institute, Kericho, Kenya \\ ${ }^{4}$ Association for Strengthening Agricultural Research in Eastern and Central Africa, Entebbe, Uganda \\ Email: "kelvinmoseti@gmail.com, "kmoseti@tearesearch.or.ke
}

Received 3 November 2015; accepted 11 January 2016; published 14 January 2016

Copyright (C) 2016 by authors and Scientific Research Publishing Inc.

This work is licensed under the Creative Commons Attribution International License (CC BY). http://creativecommons.org/licenses/by/4.0/

(c) () Open Access

\section{Abstract}

Tea seeds resulting from the cultivation of tea in many parts of the world, often regarded as waste, have been found to contain oil of exceptional quality that can be harnessed for use as an oleochemical or chemical intermediate. A comparative study was carried out to examine the free fatty acid profiles of crude oils chemically extracted by Soxhlet extraction from tea seeds collected from different cultivars of Kenyan tea. All the tea seeds of the studied tea cultivars yielded oil, though to different extents $(p>0.05)$ after the 8-hour extraction. The oils were golden yellow in color. The contents of oleic, linoleic and stearic acids in all the crude test oils have no significant difference ( $p>0.05$ ) from each other. However, statistically significant differences $(p<0.05)$ in the linolenic and palmitic acids contents were evident. Based on the current findings, the test tea oils were predominantly constituted of unsaturated fatty acids, oleic acid being the major unsaturated fatty acid, other fatty acids being present in different but smaller proportions.

\section{Keywords}

Soxhlet Extraction, TSO, GC, FAMEs, Clonal Variations

\footnotetext{
${ }^{*}$ Corresponding author.
}

How to cite this paper: George, K.O., Wanyoko, J.K., Kinyanjui, T., Moseti, K.O. and Wachira, F.N. (2016) Comparative Assessment of the Fatty Acid Profiles of Crude Oils Extracted from Seeds of Selected Tea (Camellia sinensis L.) Cultivars. Food and Nutrition Sciences, 7, 1-7. http://dx.doi.org/10.4236/fns.2016.71001 


\section{Introduction}

The tea plant is mainly cultivated for its prolific vegetative growth [1] from which different types of tea products have been processed viz., white tea [2] green tea [3], oolong tea, black tea [4] [5] among others. However, the tea plant also produces seeds from which high quality Tea Seed Oil (TSO), commonly referred to as camellia oil, can be pressed or extracted using suitable solvent(s) or solvent systems [6]-[9] with tea seed cake and husks as by-products. It is an edible, pale amber-green or golden vegetable oil and its physico-chemical properties as well as those of the above by-products have been investigated and [6] [9]-[13]. Further, various studies have reported wide range findings on extracts of flowers and stem barks of the tea plant, though to a less extent [14]-[17].

Kenya has continued to be a producer of processed tea at the primary level with very little product differentiation and value addition. This has led to constrained growth in profitability of the local tea sub-sector. Thus, the need for value addition and product diversification of locally produced tea products in a bid to reshape the future of this key industry cannot be understated. Indeed, the need for researchers and tea industry stakeholders in Kenya to exploit TSO as an avenue to ease on the current dwindling returns to tea farmers resulting from global overproduction of black tea is the need of the day. In line with these, recent research findings of collaborative research by scientists from the Kenya Agricultural and Livestock Research Organization-Tea Research Institute (KALRO-TRI), formerly the Tea Research Foundation of Kenya (TRFK) and Egerton University, a leading institution of higher learning in agricultural research, focusing on the characterization of TSO extracted from seeds of different Kenyan tea cultivars and by-products of the same process have been reported [6] [9]-[12].

From a nutritional point of view, TSO is one of the important vegetable oils because of its high contents of unsaturated fatty acids, especially essential linoleic acid, which is reported to lower blood cholesterol levels. It also has a little amount of linolenic acid, which is an important factor in rancidity and off-flavor of oils during storage [18]. However, literature available on TSO of Kenyan origin only shows how oil content, as well as the other physco-chemical properties varies from one clone to the next but not the free fatty acid composition. Thus, the intent of the current study was to quantitatively estimate the fatty acid profiles of crude TSO's extracted from seeds of selected Kenyan tea clones and it is expected that its findings will immensely contribute to the development of diversified products from the tea plant.

\section{Materials and Methods}

\subsection{Chemicals}

Authenticcommercialfatty acids standards viz., oleic acid (cis-9-Octadecenoic acid), linoleic acid (cis-9,cis-12Octadecadienoic acid), linolenic acid (cis,cis,cis-9,12,15-Octadecatrienoic acid), palmitic acid (Hexadecanoic acid) and stearic acid (Octadecanoic acid), all of analytical standard grade and purity $\geq 98.5 \%$ were purchased from Sigma Aldrich, Germany via Kobian Kenya Ltd., Nairobi. Also, the following chemicals were used; $n$ hexane ( $\geq 99.5 \%$ ), methanol ( $\geq 99.5 \%$ ), boron tri-fluoride ( $\geq 99.5 \%$ ), sodium hydroxide, heptadecanoic acid, sodium chloride and nitrogen gas (99.9\%). Double distilled water was used in all dilutions throughout the study.

\subsection{Tea Seeds}

A completely randomized design with three replicates was adopted for this study. Mature, healthy tea seeds from eight randomly selected cultivars of tea viz., TRFK 301/3, TRFK 301/4, TRFK 301/5, GW-Ejulu, TRFK K-Purple, TRFK 306, TRFK 91/1 and TRFCA SFS 150, were harvested in triplicates from mature, healthy tea plants from Timbilil Estate seed barie of KALRO-TRI, Kericho, Kenya. Each replicate for each cultivar studied was obtained from a randomly selected tea plant. The tea seeds were dried under ambient conditions to a constant weight and then manually de-husked. The husks were separated manually from the seed kernels. Low quality kernels were also manually separated from the good quality ones. The desired tea seed kernels were then milled using an electric blender (Philips HL7510/00, Netherlands) for particle size reduction and test sample homogenization.

\subsection{Oil Extraction}

Oil extraction was achieved using the solvent extraction method described by [6] [9]. A standard soxhlet apparatus set-up was used employing $n$-hexane as the solvent of choice and a solid:solvent ratio of 1:20. The extrac- 
tion duration was 8 hours after which the $n$-hexane extract was concentrated by rotary evaporation at $60^{\circ} \mathrm{C} \pm$ $0.5^{\circ} \mathrm{C}$ using a rotary evaporator (Model R-3000, Buchi, Switzerland) and then placed in an oven at $80^{\circ} \mathrm{C} \pm 0.5^{\circ} \mathrm{C}$ for an hour to evaporate any residual solvent. The crude TSO extracts were allowed to cool to room temperature in well dessicated dessicators after which they were transferred into well labeled sample bottles. A stream of nitrogen gas was blown into the head space of the sample bottles containing the crude TSO extracts, tightly closed and stored under refrigeration $\left(-15^{\circ} \mathrm{C} \pm 0.5^{\circ} \mathrm{C}\right)$ awaiting analysis. The color of the crude oil extracts were carefully observed and noted.

\subsection{Fatty Acid Analyses}

The fatty acid profiles of the crude test oils were determined as Fatty Acid Methyl Esters (FAMEs) by Gas Chromatography (GC). Approximately $0.5 \mathrm{mg}$ of the test TSO was weighed into a clean and dry $250 \mathrm{~mL}$ roundbottomed flask fitted with a reflux condenser. To the test oil, $5.0 \mathrm{~mL}$ of $0.5 \mathrm{M}$ methanolic sodium hydroxide was added and the mixture boiled under reflux for 10 minutes. Via the condenser, $10 \mathrm{~mL}$ of boron tri-fluoride was added and the mixture was refluxed for a further 3 minutes. Subsequently, $5.0 \mathrm{~mL}$ of $n$-hexane was then added via the condenser to the mixture and boiled under reflux for a further 3 minutes. The heating source was then removed after which $5.0 \mathrm{~mL}$ of saturated sodium chloride solution was added to the mixture. $1.0 \mathrm{~mL}$ of the $n$-hexane layer was transferred into a clean test tube. Equal weights of the sample and fatty acid standards $(0.20$ $\pm 0.01 \mathrm{~g}$ ) were weighed into clean test tubes and were both diluted with same amount of an internal standard (heptadecanoic acid). Since the same mass of the internal standard is added to both the sample and the standard solution, the mass of the internal standard does not come into the calculation of the assay.

The chromatographic system used to quantitatively estimate the FAMEs derived from the authentic commercial fatty acids' standards and crude test TSO's constituted of a Varian 3300 gas chromatograph equipped with a Flame Ionization Detector (FID) and fitted with a column (30 $\mathrm{m} \times 0.32 \times 0.25 \mu \mathrm{m}$ i.d.) packed with chromosorb WAW 60 - 80 mesh (percolated with 15\% diethyl glycol succinate) and a Varian integrator (Varian 4290) as the read out. The column (DB-wax column) was first conditioned by passing nitrogen gas through at $180^{\circ} \mathrm{C} \pm 0.5^{\circ} \mathrm{C}$ for 5 hours. The chromatographic operating conditions used were; the nitrogen and hydrogen flow rates were both $40.0 \mathrm{~mL} \cdot \mathrm{min}^{-1}$, the air flow rate was $30.0 \mathrm{~mL} \cdot \mathrm{min}^{-1}$, the injection volume was $3.0 \mu \mathrm{L}$ and the injector, column and detector temperatures were $240^{\circ} \mathrm{C} \pm 0.5^{\circ} \mathrm{C}, 180^{\circ} \mathrm{C} \pm 0.5^{\circ} \mathrm{C}$ and $260^{\circ} \mathrm{C} \pm 0.5^{\circ} \mathrm{C}$ respectively. The fatty acids were identified based on their retention times compared with those of the FAMEs derived from the authentic commercial fatty acids' standards. Percentage assay for the compounds were calculated using the relation;

$$
\frac{\mathrm{P}_{\mathrm{A}} \text { of } \mathrm{A} \text { in sample } / \mathrm{P}_{\mathrm{A}} \text { of I.S in sample } \times \text { weight of standard } \times \% \text { purity of standard }}{\mathrm{P}_{\mathrm{A}} \text { of } \mathrm{A} \text { in standard } / \mathrm{P}_{\mathrm{A}} \text { of I.S in standard } \times \text { weight of sample }}
$$

where $\mathrm{A}$ is the compound being analyzed (analyte), $\mathrm{P}_{\mathrm{A}}$ is the peak area of the analyte and I.S is the internal standard.

\subsection{Data Analysis}

Data obtained were subjected to analysis of variance (ANOVA) using MSTAT statistical package version 2.10 at $\mathrm{p}<0.05$. The least significant difference (LSD) test was used in mean separation where statistically significant differences were recorded. Data are tabulated as means of triplicate determinations \pm standard deviation (SD).

\section{Results and Discussion}

The tea seeds obtained from the cultivars under study were observed to be of different sizes and appearance as shown and described in Figure 1(a) and Figure 1(b) and Table 1 respectively. Larger seeds were noted in TRFK 301 series, TRFK 91/1 and TRFK 306, while small-sized seeds noted in TRFCA SFS 150, GW-Ejulu and TRFK K-Purple clones [Figure 1(a) and Figure 1(b)].

All the tea seeds of the studied tea cultivars yielded oil, though to different extents $(p>0.05)$ after the 8 hour solvent extraction an observation noted by [6]. All the oils extracted were in the liquid phase at ambient conditions. The crude test oils were golden yellow in colour. Crude TSO of clone TRFK 91/1 solidified under refri- 


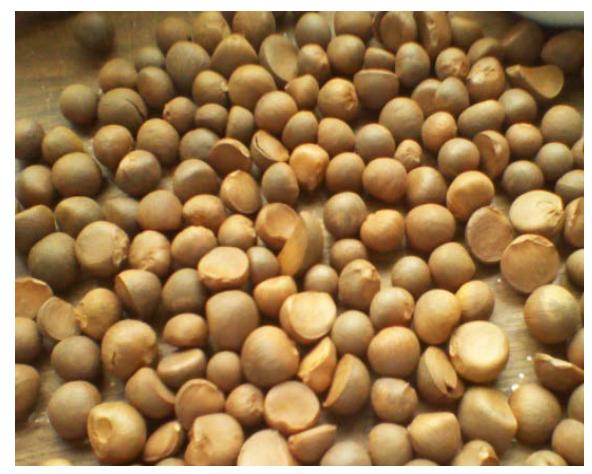

(a)

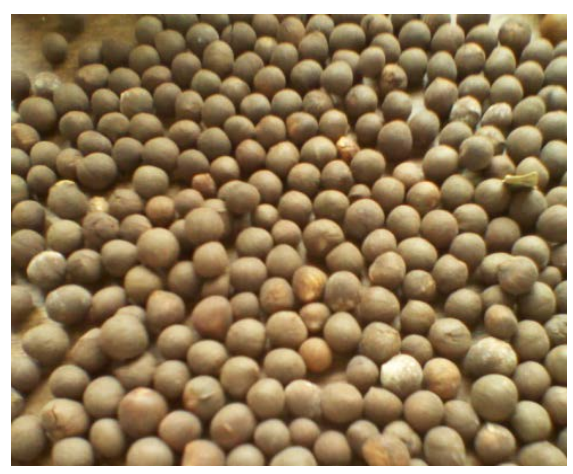

(b)

Figure 1. (a) and (b) A general representation of the sizes and appearance of the test tea seeds.

Table 1. A descriptive representation of the size and appearance of the tea seeds collected from the eight Kenyan tea cultivars under studyable type styles.

\begin{tabular}{cc}
\hline Clone & Size and appearance \\
\hline TRFK 301/3 & Large with brown seed coat \\
TRFK 301/4 & Large with brown seed coat \\
TRFK 301/5 & Large with brown seed coat \\
GW-Ejulu & Small with dark brown seed coat \\
TRFK K-Purple & Smallest with dark brown seed coat \\
TRFK 306 & Large with brown seed coat \\
TRFK 91/1 & Large with brown seed coat \\
TRFCA SFS 150 & Small with brown seed coat \\
\hline
\end{tabular}

geration after 7 days of storage. Crude TSO from the seeds of cultivar's TRFCA SFS 150 and TRFK 301/5 also solidified but to a lesser extent on refrigeration compared to TSO of clone TRFK 91/1. The rest of the oils remained in the liquid phase under the same conditions.

Figure 2 is a representative chromatogram of the fatty acid profile for the test crude oil extracted from clone TRFK 301/4. The fatty acid profiles of all the crude TSO's of the studied cultivars were as tabulated (Table 2). Evidently, there was no significant difference $(p>0.05)$ in the levels of oleic, linoleic and stearic acids in all the crude test oils (Table 2). However, significant differences $(\mathrm{p}<0.05)$ in the linolenic, palmitic and the other fatty acids were observed. For instance, significant differences $(\mathrm{p}<0.05)$ were recorded in the levels linolenic acid in the crude test oils from seeds of clones TRFK 301/4 and TRFCA SFS 150 with the former having the highest linolenic acid content $(2.8 \% \pm 0.1 \%)$. The rest of the crude test oils had no significant difference $(p>0.05)$ in their linoleic acid contents. Further, it is evident that there was no significant difference $(p>0.05)$ in the levels of palmitic acid in the crude test oils of cultivars' TRFK 91/1, 301/3 and 301/5 which had $21.7 \% \pm 1.6 \%$, 21.7\% $\pm 0.7 \%$ and $22.3 \% \pm 0.4 \%$ palmitic acid respectively. On the other hand, clone TRFK 301/4 that had the lowest palmitic acid content $(19.5 \% \pm 1.8 \%)$.

Previous studies have reported the tea (Camellia sinensis) plant to produce tea seeds from which TSO can be harnessed [6] [7] [19] [20] as well as other potentially useful by products, mainly the tea seed cake and husks [10]-[12]. Further, a number of potential positive health effects for continued use of this oil have been investigated and reported, most notably the anti-oxidant activity [1] [8] [21] [22]. Indeed, prospect of the use of TSO in the production of biodiesel has been investigated and reported [23].

In a similar study, [7] report TSO to comprise of $25.7 \%$ saturated fatty acids and $73.3 \%$ unsaturated fatty acids. This data strongly agrees with the current study's findings where we report crude Kenyan test TSO's to comprise an average of $74.2 \%$ and $24.5 \%$ unsaturated and saturated fatty acids fatty acids respectively. However, tea (Camellia oleifera) seed oil has been reported to be comprised of between $82 \%$ and $84 \%$ unsaturated fatty 


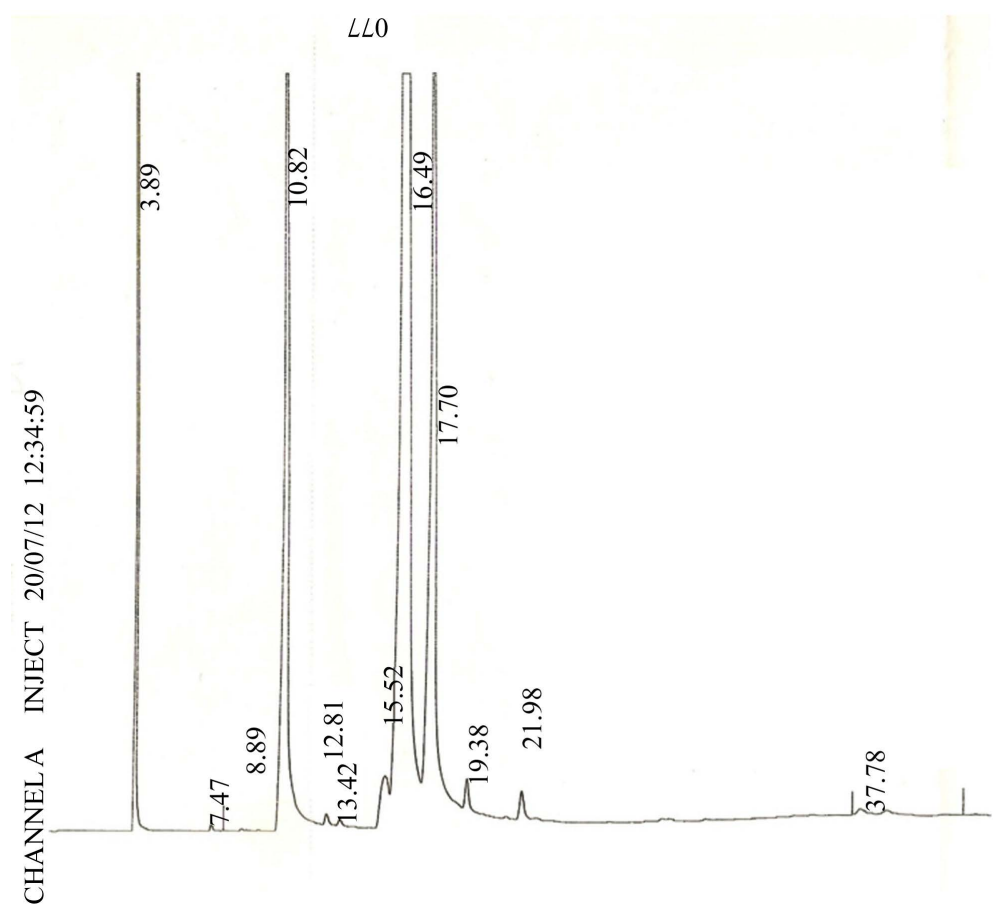

Figure 2. A representative GC chromatogram of the fatty acids in crude TSO extracted from clone TRFK 301/4.

Table 2. Profiles of fatty acids in in percentage the crude TSO's extracted from the seeds of different cultivars of Kenyan tea expressed as a mean of the triplicate determinations \pm standard deviation.

\begin{tabular}{ccccccc}
\hline Cultivar & Oleic & Linoleic & Linolenic & Palmitic & Stearic & Others \\
\hline TRFK 91/1 & ${ }^{*} 57.7 \pm 0.8$ & ${ }^{\mathrm{a}} 13.6 \pm 0.8$ & ${ }^{\mathrm{ab}} 2.0 \pm 0.8$ & ${ }^{\mathrm{a}} 21.7 \pm 1.6$ & ${ }^{\mathrm{a}} 3.6 \pm 1.1$ & ${ }^{\mathrm{ab}} 1.5 \pm 0.8$ \\
TRFK 301/3 & ${ }^{\mathrm{a}} 60.0 \pm 1.3$ & ${ }^{\mathrm{a}} 12.8 \pm 0.9$ & ${ }^{\mathrm{ab}} 1.4 \pm 0.5$ & ${ }^{\mathrm{a}} 21.7 \pm 0.7$ & ${ }^{\mathrm{a}} 3.0 \pm 0.7$ & ${ }^{\mathrm{ab}} 1.1 \pm 0.7$ \\
TRFK 301/4 & ${ }^{\mathrm{a}} 60.6 \pm 2.6$ & ${ }^{\mathrm{a}} 13.7 \pm 1.3$ & ${ }^{\mathrm{a}} 2.8 \pm 0.1$ & ${ }^{\mathrm{b}} 19.5 \pm 1.8$ & ${ }^{\mathrm{a}} 2.7 \pm 0.9$ & $0.9 \pm 0.1$ \\
TRFK 301/5 & ${ }^{\mathrm{a}} 56.5 \pm 3.2$ & ${ }^{\mathrm{a}} 15.0 \pm 1.8$ & ${ }^{\mathrm{ab}} 2.3 \pm 1.1$ & ${ }^{\mathrm{a}} 22.3 \pm 0.4$ & ${ }^{\mathrm{a}} 3.1 \pm 0.3$ & ${ }^{\mathrm{b}} 0.7 \pm 0.2$ \\
GW-Ejulu & ${ }^{\mathrm{a}} 57.9 \pm 4.9$ & ${ }^{\mathrm{a}} 13.3 \pm 1.3$ & ${ }^{\mathrm{ab}} 2.0 \pm 1.1$ & ${ }^{\mathrm{ab}} 21.4 \pm 1.2$ & ${ }^{\mathrm{a}} 2.8 \pm 0.5$ & ${ }^{\mathrm{a}} 2.6 \pm 1.5$ \\
TRFK K-Purple & ${ }^{\mathrm{a}} 58.9 \pm 3.8$ & ${ }^{\mathrm{a}} 13.6 \pm 0.7$ & ${ }^{\mathrm{ab}} 1.6 \pm 1.0$ & ${ }^{\mathrm{ab}} 21.2 \pm 0.7$ & ${ }^{\mathrm{a}} 3.2 \pm 0.5$ & ${ }^{\mathrm{ab}} 1.5 \pm 1.3$ \\
TRFK 306 & ${ }^{\mathrm{a}} 58.6 \pm 2.0$ & ${ }^{\mathrm{a}} 13.4 \pm 1.3$ & ${ }^{\mathrm{ab}} 1.7 \pm 0.4$ & ${ }^{\mathrm{ab}} 20.4 \pm 0.4$ & ${ }^{\mathrm{a}} 4.2 \pm 0.2$ & ${ }^{\mathrm{ab}} 1.7 \pm 0.3$ \\
TRFCA SFS 150 & ${ }^{\mathrm{a}} 59.3 \pm 1.0$ & ${ }^{\mathrm{a}} 13.7 \pm 0.9$ & ${ }^{\mathrm{b}} 1.1 \pm 0.2$ & ${ }^{\mathrm{ab}} 21.0 \pm 0.9$ & ${ }^{\mathrm{a}} 4.1 \pm 1.3$ & ${ }^{\mathrm{b}} 0.8 \pm 0.3$ \\
Mean & 58.7 & 13.6 & 1.9 & 21.2 & 3.3 & 1.3 \\
CV (\%) & 5.1 & 8.9 & 43.4 & 5.0 & 24.1 & 62.6 \\
LSD (p $\geq \mathbf{0 . 0 5 )}$ & 5.8 & 2.4 & 1.6 & 2.0 & 1.6 & 1.6 \\
\hline
\end{tabular}

*Means within a column preceded with the same letter are not statistically significantly different $(\mathrm{p}>0.05)$.

acid [24], values significantly higher than the findings of the present work. Moreover, it has been previously reported that Camellia oils have a similar fatty acid composition as that of olive oil, high in oleic acid, which could reach over $80 \%$ [25]. Thus, the fatty acid profile of TSO makes it a direct competitor for Canola and olive oils.

The highlighted differences in the fatty acid composition and consequently profiles in the current study and published literature can be attributed to a number of factors including geographical and varietal differences. Further, tea (Camellia sinensis) seed oil extracted by superficial carbon dioxide $\left(\mathrm{SC}-\mathrm{CO}_{2}\right)$ method has $80 \%$ un- 
saturated fatty acid and has the strongest scavenging ability on the DPPH radical than the one extracted by Soxhlet method [8]. This value is also higher than the one obtained from this research work and could be attributed to the difference in the method of extraction of the oil. Other factors that may influence the chemical composition and hence the quality of TSO have been reported; for instance, [26] report the effect of roasting as a pre-treatment step between the milling and de-hulling stages, their results suggesting that adequate roasting treatments can improve the quality of Camellia oil and make it to be oxidatively more stable. Generally, pretreatment operations involved in the extraction of oil from seeds, starting from cleaning, dehusking, drying and grinding may have great influence on the chemical properties and as such quality.

\section{Conclusion}

All the crude oils extracted from seeds of the selected tea cultivars contain oil, though to different extents. The color of the oils was golden yellow. The test tea oils predominantly constituted of unsaturated fatty acids, oleic acid being the majorone. Other fatty acids were present in different but smaller proportions, that is, high-oleic, medium-linoleic and low-linolenic acid contents. The fatty acid profiles of the crude test oils studied suggest that TSO optimally extracted can be a good source of edible oil with suitable nutritional properties.

\section{Acknowledgements}

The authors appreciate the financial support of the Kenya Agricultural and Livestock Research OrganizationTea Research Institute (KALRO-TRI). The technical assistance Mr. S. K. Mwangi with chromatographic analyses is gratefully acknowledged.

\section{References}

[1] Sahari, M. and Amooi, M. (2013) Tea Seed Oil: Extraction, Compositions, Applications, Functional and Antioxidant Properties. Academia Journal of Medicinal Plants, 1, 68-79.

[2] Hilal, Y. and Engelhardt, U. (2007) Characterisation of White Tea-Comparison to Green and Black Tea. Journal of Consumer Protection and Food Safety, 2, 414-421. http://dx.doi.org/10.1007/s00003-007-0250-3

[3] Rusak, G., Komes, D., Likić, S., Horžić, D. and Kovač, M. (2008) Phenolic Content and Antioxidative Capacity of Green and White Tea Extracts Depending on Extraction Conditions and the Solvent Used. Food Chemistry, 110, 852858. http://dx.doi.org/10.1016/j.foodchem.2008.02.072

[4] Sang, S., Lambert, J.D., Ho, C.T. and Yang, C.S. (2011) The Chemistry and Biotransformation of Tea Constituents. Pharmacological Research, 64, 87-99. http://dx.doi.org/10.1016/j.phrs.2011.02.007

[5] Coe, S., Fraser, A. and Ryan, L. (2013) Polyphenol Bioaccessibility and Sugar Reducing Capacity of Black, Green, and White Teas. International Journal of Food Science, 2013, Article ID: 238216. http://dx.doi.org/10.1155/2013/238216

[6] George, K.O., Kinyanjui, T., Wanyoko, J., Moseti, O.K. and Wachira, F. (2013) Extraction and Analysis of Tea (Camellia sinensis) Seed Oil from Different Clones in Kenya. African Journal of Biotechnology, 12, 841-846.

[7] Yahaya, L.E., Adebowale, K.O., Olu-Owolabi, B.I. and Menon, A.R.R. (2011) Compositional Analysis of Tea (Camellia sinensis) Seed Oil and Its Application. International Journal of Research in Chemistry and Environment, 1, 153158.

[8] Wang, Y., Sun, D., Chen, H., Qian, L. and Xu, P. (2011) Fatty Acid Composition and Antioxidant Activity of Tea (Camellia sinensis L.) Seed Oil Extracted by Optimized Supercritical Carbon Dioxide. International Journal of Molecular Sciences, 12, 7708-7719. http://dx.doi.org/10.3390/ijms12117708

[9] George, K.O., Moseti, K.O., Wanyoko, J.K., Kinyanjui, T. and Wachira, F.N. (2015) Quantitation of the Total Catechin Content in Oils Extracted from Seeds of Selected Tea (Camellia sinensis (L) O. Kuntze, Theaceae) Clones by RP-HPLC. American Journal of Plant Sciences, 6, 1080-1089. http://dx.doi.org/10.4236/ajps.2015.67112

[10] Njuguna, D.G., Wanyoko, J.K., Kinyanjui, T. and Wachira, F.N. (2013) Mineral Elements in the Kenyan Tea Seed Oil Cake. International Journal of Research in Chemistry and Environment, 3, 253-261.

[11] Njuguna, D.G., Wanyoko, J.K., Kinyanjui, T. and Wachira, F.N. (2013) Polyphenols and Free Radical Scavenging Properties of Kenyan Tea Seed Oil Cake. International Journal of Research in Chemistry and Environment, 3, 86-92.

[12] Njuguna, D.G., Wanyoko, J.K., Kinyanjui, T. and Wachira, F.N. (2014) Fatty Acids Residues Composition in the De-Oiled Tea Seed Oil Cakes. Science Journal of Biotechnology, 2014, Article ID: sjbt-263.

[13] Zarringhalami, S., Sahari, M.A., Barzegar, M. and Hamidi-Esfehani, Z. (2011) Changes in Oil Content, Chemical Properties, Fatty Acid Composition and Triacylglcerol Species of Tea Seed Oil during Maturity Period. Journal of 
Food Biochemistry, 35, 1161-1169. http://dx.doi.org/10.1111/j.1745-4514.2010.00442.x

[14] Yang, Z., Xu, Y., Jie, G., He, P. and Tu, Y. (2007) Study on the Antioxidant Activity of Tea Flowers (Camellia sinensis). Asia Pacific Journal of Clinical Nutrition, 16, 148-152.

[15] Chen, B.T., Li, W.X., He, R.R., Li, Y.F., Tsoi, B., Zhai, Y.J. and Kurihara, H. (2012) Anti-Inflammatory Effects of a Polyphenols-Rich Extract from Tea (Camellia sinensis) Flowers in Acute and Chronic Mice Models. Oxidative Medicine and Cellular Longevity, 2012, Article ID: 537923. http://dx.doi.org/10.1155/2012/537923

[16] Zhang, X., Gao, Y., Xu, J., Liu, X., Jin, F., Li, B. and Tu, Y. (2014) Inhibitory Effect of Tea (Camellia sinensis (L.) O. Kuntze, Theaceae) Flower Extracts on Oleic Acid-Induced Hepatic Steatosis in Hepg2 Cells. Journal of Food and Nutrition Research, 2, 738-743. http://dx.doi.org/10.12691/jfnr-2-10-13

[17] Ochanda, S.O., Faraj, A.K., Wanyoko, J.K., Onyango, C.A. and Ruto, H.K. (2015) Extraction and Quantification of Total Polyphenol Content in Different Parts of Selected Tea Cultivars. American Journal of Plant Sciences, 6, 15811586. http://dx.doi.org/10.4236/ajps.2015.69158

[18] Gecgel, U., Demirci, M., Esendal, E. and Tasan, M. (2007) Fatty Acid Composition of the Oil from Developing Seeds of Different Varieties of Safflower (Carthamus tinctorius L.). Journal of the American Oil Chemists' Society, 84, 4754. http://dx.doi.org/10.1007/s11746-006-1007-3

[19] Owuor, P.O., Chavanji, A.M. and Munavu, R.M. (1985) Chemical Studies of the Kenyan Tea Seeds. I. Physical and Chemical Characteristics of the Kernel Oil. Tea, 6, 23-28.

[20] Demibras, A. (2009) Oil from Tea Seed by Supercritical Fluid Extraction. Energy Sources, Part A: Recovery, Utilization, and Environmental Effects, 31, 217-222. http://dx.doi.org/10.1080/15567030701524340

[21] Fazel, M., Sahari, M.A. and Barzegar, M. (2009) Comparison of Tea and Sesame Seed Oils as Two Natural Antioxidants in a Fish Oil Model System by Radical Scavenging Activity. International Journal of Food Sciences and Nutrition, 60, 567-576. http://dx.doi.org/10.3109/09637480801987625

[22] Shao, P., Liu, Q., Fang, Z. and Sun, P. (2015) Chemical Composition, Thermal Stability and Antioxidant Properties of Tea Seed Oils Obtained by Different Extraction Methods: Supercritical Fluid Extraction Yields the Best Oil Quality. European Journal of Lipid Science and Technology, 117, 355-365. http://dx.doi.org/10.1002/ejlt.201400259

[23] Demirbas, A. (2010) Tea Seed Upgrading Facilities and Economic Assessment of Biodiesel Production from Tea Seed Oil. Energy Conversion and Management, 51, 2595-2599. http://dx.doi.org/10.1016/j.enconman.2010.05.025

[24] Ma, J., Ye, H., Rui, Y., Chen, G. and Zhang, N. (2011) Fatty Acid Composition of Camellia oleifera Oil. Journal Für Verbraucherschutz Und Lebensmittelsicherheit, 6, 9-12. http://dx.doi.org/10.1007/s00003-010-0581-3

[25] Haiyan, Z., Bedgood, D.R., Bishop, A.G., Prenzler, P.D. and Robards, K. (2007) Endogenous Biophenol, Fatty Acid and Volatile Profiles of Selected Oils. Food Chemistry, 100, 1544-1551. http://dx.doi.org/10.1016/j.foodchem.2005.12.039

[26] Hsieh, C., Yang, J., Chuang, Y., Wang, E.I. and Lee, Y. (2013) Effects of Roasting Prior to Pressing on the Camellia Oil Quality. Journal of Taiwan Agricultural Research, 62, 249-258. 